\title{
Estimation of Runup Heights of the 2011 off the Pacific Coast of Tohoku Earthquake Tsunami Based on Numerical Simulations
}

\author{
Byung Ho Choi ${ }^{1}$, Efim Pelinovsky ${ }^{*}, 2,3$, Kyeong Ok Kim ${ }^{4}$ and Byung Il Min ${ }^{5}$ \\ ${ }^{I}$ Department of Civil and Environmental Engineering, Sungkyunkwan University, Korea \\ ${ }^{2}$ Department of Applied Mathematics, Nizhny Novgorod State Technical University, Nizhny Novgorod, Russia \\ ${ }^{3}$ Department of Nonlinear Geophysical Processes, Institute of Applied Physics, Nizhny Novgorod, Russia \\ ${ }^{4}$ Marine Environments \& Conservation Research Division, Korea Institute of Ocean Science \& Technology, Ansan, \\ Korea \\ ${ }^{5}$ Nuclear Environment Safety Research Division, Korea Atomic Energy Research Institute, Daejeon, Korea
}

\begin{abstract}
A strong earthquake (M9.0) occurred at 14 h 46 m (JST) on March 11, 2011 in the Pacific Ocean east of the Tohoku district in the northeast part of Honshu Island, Japan. The earthquake was accompanied by a large tsunami. The main goal of this study is to use numerical modelling to reproduce the observed characteristics of the 2011 tsunami. First, the water elevation records of DART buoys, coastal tidal gauges and GPS wave buoys are compared with the numerical simulation. Then, the observed runup heights that were published by the Joint Survey Group are compared with the results of the numerical simulations in the Pacific coast of the Tohoku district. For tsunami modelling in ocean and coastal zone, numerical computations were performed with the Princeton Ocean Model (POM). The finite fault model of the U.S. Geological Survey is chosen to reproduce the tsunami source. For computing the runup height, the time series of the water height that were determined by the numerical model in the last sea grid points were converted by the $1 \mathrm{D}$ analytical nonlinear theory of long-wave runup. The computed runup heights on the shore roughly correlate with the observed runup heights, with the exception of the northern Miyagi Prefecture, which was directly hit by the tsunami.
\end{abstract}

Keywords: Tsunami, shallow-water theory, numerical modeling, runup height, 2011 off the Pacific Coast of Tohoku Earthquake, rapid forecasting, DART buoy

\section{INTRODUCTION}

An earthquake occurred at $14 \mathrm{~h} 46 \mathrm{~m}$ (JST) on March 11, 2011 in the Pacific Ocean east of the Tohoku district in the northeast part of Honshu Island, Japan. The magnitude of the earthquake was M 9.0, which is reported to be the fourth largest earthquake since the Chilean earthquake in 1960. The epicentre of the earthquake was between the Pacific and North American tectonic plates. An enormous tsunami resulted from the 2011 Tohoku earthquake. The tsunami struck shore on the northeast coast of Japan (e.g., Iwate, Miyagi, and Fukushima) within one hour. The tsunami runup led to massive losses of life and infrastructure in Japan.

The Japan Society of Civil Engineers (JSCE) performed post-tsunami runup surveys. The purpose of these surveys was to observe and document the effects of tsunamis, collect perishable data on the nature and impact of the phenomenon, and enable recommendations on the need for further

\footnotetext{
*Address correspondence to this author at the Institute of Applied Physics, Russian Academy of Sciences, 46 Uljanov Street, 603950 Nizhny Novgorod, Russia, Nizhny Novgorod State Technical University, 24 Minin Street, 603600 Nizhny Novgorod, Russia, High School of Economics, 52 B Pecherskaya, 603600 Nizhny Novgorod, Russia; Tel: +7-831-4164839; Fax: +7-831-4365976; E-mail: pelinovsky@hydro.appl.sci-nnov.ru
}

research, planning and preparedness. The data from these surveys were compiled to provide the geographical locations and runup heights on the Internet (http://www.coastal.jp/ tsunami2011). This nationwide tsunami survey was conducted by 299 researchers from 64 universities and institutes. A total of 5,282 measured points of inundation and runup height were provided in the recently released data on $7 \mathrm{Au}-$ gust 2012. The results of the field survey have been summarised $[1,2]$.

In the Iwate areas, many V-shaped valleys open to the northeast Pacific Ocean. The high measured runups were found at the tip of a small V-shaped valley, and these were undoubtedly a local effect. The tsunami waves pushed into $\mathrm{V}$-shaped valleys that were open to the seas, which concentrated the water into increasingly tighter spaces. Ultimately, the water runup was more than 20 metres above sea level. These natural phenomena have been observed in previous tsunami field surveys. For example, an earthquake in the East (Japan) Sea southwest of Hokkaido (M 8.3) caused a 30 m runup height on the west coast of Okushiri Island [3].

A rapid method of numerically estimating tsunami runup heights has been suggested in our cooperation $[4,5]$. This method is based on matching the solutions for the water displacement of a $2 \mathrm{D}$ numerical shallow-water model with a 
non-flux boundary condition near the shore and a 1D analytical nonlinear theory of long-wave runup. This procedure has been rigorously proved only for weak-amplitude waves above the plane beach and with no friction. The method has shown good correlation with the observed runup heights of the 1983 tsunami along the East Korean coast in the East (Japan) Sea. The approach will be applied in the present paper to estimate the runup characteristics of the 2011 tsunami on the Japanese coast. In Section 2, the tsunami numerical model that used in our simulations is described. In Section 3, the results of the numerical modelling of the tsunami wave characteristics are compared with instrumental records on DART buoys and tidal gauges on the East Japan coast. Computations of the runup heights and a comparison with the observed runup data is provided in Sections 4 and 5.

\section{MODEL CONFIGURATION AND EXPERI- MENTAL DESIGN}

The free-surface sigma-coordinate Princeton Ocean Model [6, 7] was applied to tsunami modelling in the ocean selecting the Pacific and Japanese coastal areas (Fig. 1). We organised the Pacific domain to verify the tsunami source model with DART buoys and tidal gauges, and we organised the Japan coast domain to compute the tsunami wave characteristics on the coast. The tsunami simulation of the Pacific domain, which is indicated by the red square box in Fig. (1), is performed within the framework of the $2 \mathrm{D}$ mode of Princeton Ocean Model with a time step of $1 \mathrm{sec}$ and a 2 arcminute (approximately $3 \mathrm{~km}$ ) grid resolution. The drag coefficient for the bottom boundary is assumed to be a constant $\left(C_{z}=0.0025\right)$. For the Japanese coast domain model, which is indicated by the black square box in Fig. (1), the Princeton Ocean Model with 10 vertical sigma levels, the value of the drag coefficient provided by [6] and the parameterisation of turbulence from [8] is used. This domain has a high horizontal grid resolution of $30 \mathrm{sec}$ (approximately $750 \mathrm{~m}$ ) and a time step of $0.5 \mathrm{sec}$. The land boundary conditions are modelled by non-flux conditions, and the radiation boundary scheme is employed in both domains for the open boundary. A GEBCO dataset (http://www.bodc.ac.uk/products/bodc_ products/gebco) with a $30 \mathrm{sec}$ resolution is used in the bathymetry.

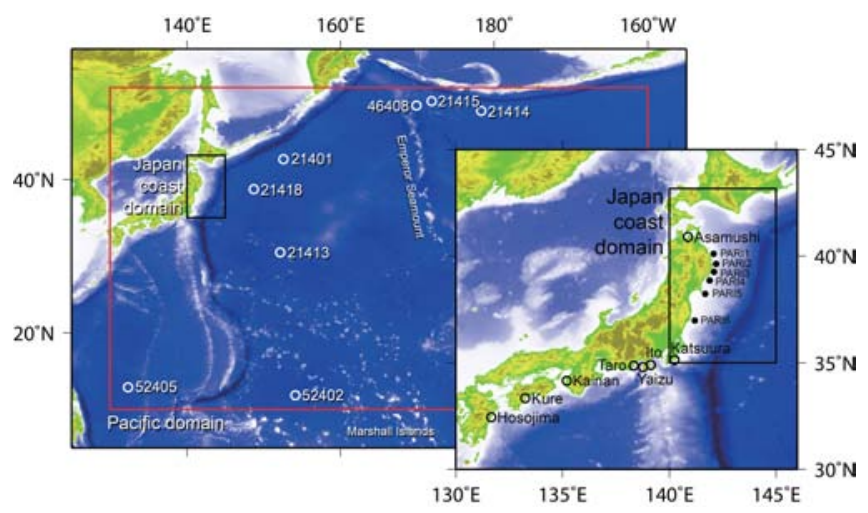

Fig. (1). Computational domains for the numerical simulation of the tsunami wave that was caused by the 2011 earthquake off the Pacific coast of Tohoku, Japan, and tsunami wave recording stations; eight DART buoys (white circle), eight tide gauges (black circle) and six GPS wave buoys (black dot). The red square box indicates the Pacific domain, and the black square box indicates the Japan coast domain.

\section{HINDCASTING THE SIMULATION OF THE TSU- NAMI PROPAGATION}

Two earthquake fault models, USGS (U.S. Geological Survey) [9] and CALT (the Seismological Laboratory at the California Institute of Technology) [10], are tested for the ocean propagation using the numerical model. Using equations derived by [11], the initial tsunami wavefield is calculated from the coseismal displacement field that was determined from the finite fault slip. The USGS model has a finite form of 25 by 13 faults that are each $25 \mathrm{~km}$ by $20 \mathrm{~km}$. The fault parameters of the CALT model were estimated in a triangle patch, so they were interpolated to a rectangular grid. Fig. (2) represents the water displacement that was calculated with Okada's formula.

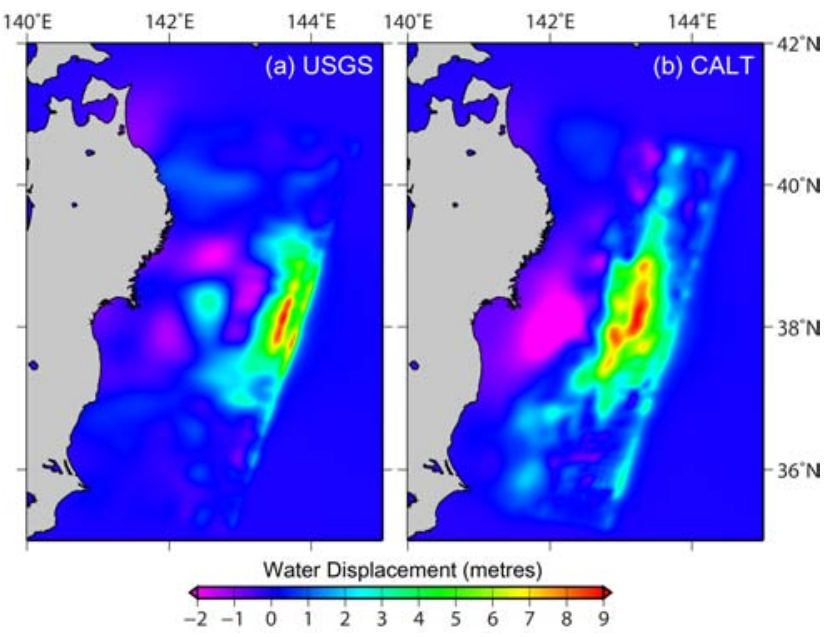

Fig. (2). The vertical water displacement that is calculated using Okada's formulation of (a) USGS and (b) CALT.

By solving the 2D mode of Princeton Ocean Model with the CALT source model, Fig. (3) shows the computed maximum tsunami heights and tsunami travel times in the Pacific domain. A large water displacement is shown around the east coast of Japan. The main energy propagation direction was east-southeast, and the large tsunami energy was interrupted by the Emperor Seamount (Fig. 3). These results are qualitatively matched with the propagation chart that was created by the National Oceanic and Atmospheric/Pacific Marine Environmental Laboratory [12].

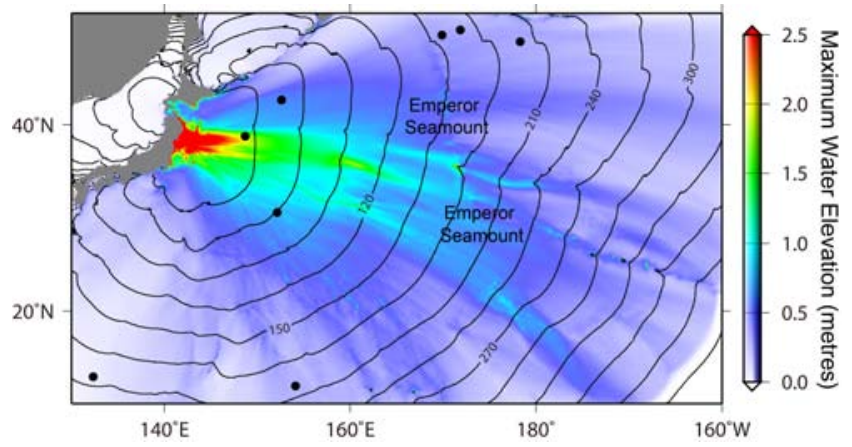

Fig. (3). Computed maximum tsunami water elevation in metres (shaded image) and tsunami travel times in minutes (contour) using the CALT source model (Simons et al., 2011). The black dots indicate the DART buoys. 
Fig. (4) shows the computed time series, using the USGS and CALT models, for the Pacific domain. The models are compared with the observed data from the eight DART buoys which are indicated in Fig. (1) and Fig. (3), and eight tidal gauges which are indicated by the black circle in Fig. (1). The observed sea level records include tide data, atmospheric effects and large-scale ocean waves. Thus, we processed the data using a band-pass filter [13] to remove the tide for the purpose of examining the details of the tsunami.

The left portion of Fig. (5) demonstrates the correlation between the observed and computed travel times for the first tsunami wave. The travel time corresponds to the time before the maximum height of the first tsunami wave. The two source models provided similar travel time results for the first tsunami wave with high accuracy (1-2\%). The right portion of Fig. (5) compares the observed first tsunami wave heights with the computed values. The CALT tsunami source provides a better correlation with the observed data than the USGS model. On average, the ratio of the computed/observed wave heights is 0.925 for the CALT model and only 0.63 for the USGS model. Underestimated patterns of the simulation results that were compared with the buoy observations are shown $[14,15]$. These authors used different estimations of the tsunami source for the 2011 earthquake tsunami off the Pacific coast of Tohoku; however, they were also unable to satisfactorily reproduce the tsunami height and arrival time with all of the available data.

\section{RUNUP HEIGHT ESTIMATIONS}

At the time of this report (September 2011), more than 5,200 water level measurements have been collected along $2,000 \mathrm{~km}$ of the Japanese coastline [16], which is the largest collection of tsunami height measurements for any single tsunami event. The data have been summarised in the IOC/UNESCO [17] reports and have been posted at NOAA's National Geophysical Data Center [18]. The highest water level was over 40 metres, which was the highest tsunami height ever measured in Japan [2]. The water heights were close to or exceeded 20 metres in the most populated coastal communities in the Iwate area [1].

To model the observed runup heights, we conducted a numerical simulation with an analytical solution that was suggested by [4]. First, the wave propagation near the coast is computed using the Princeton Ocean Model with 10 vertical sigma-coordinate levels and the CALT tsunami source. The quality of the near-shore computations is shown in Fig. (6); the observed and computed time series of water displacement at the six GPS wave buoys, which were collected by the Port and Airport Research Institute, Japan, are shown.
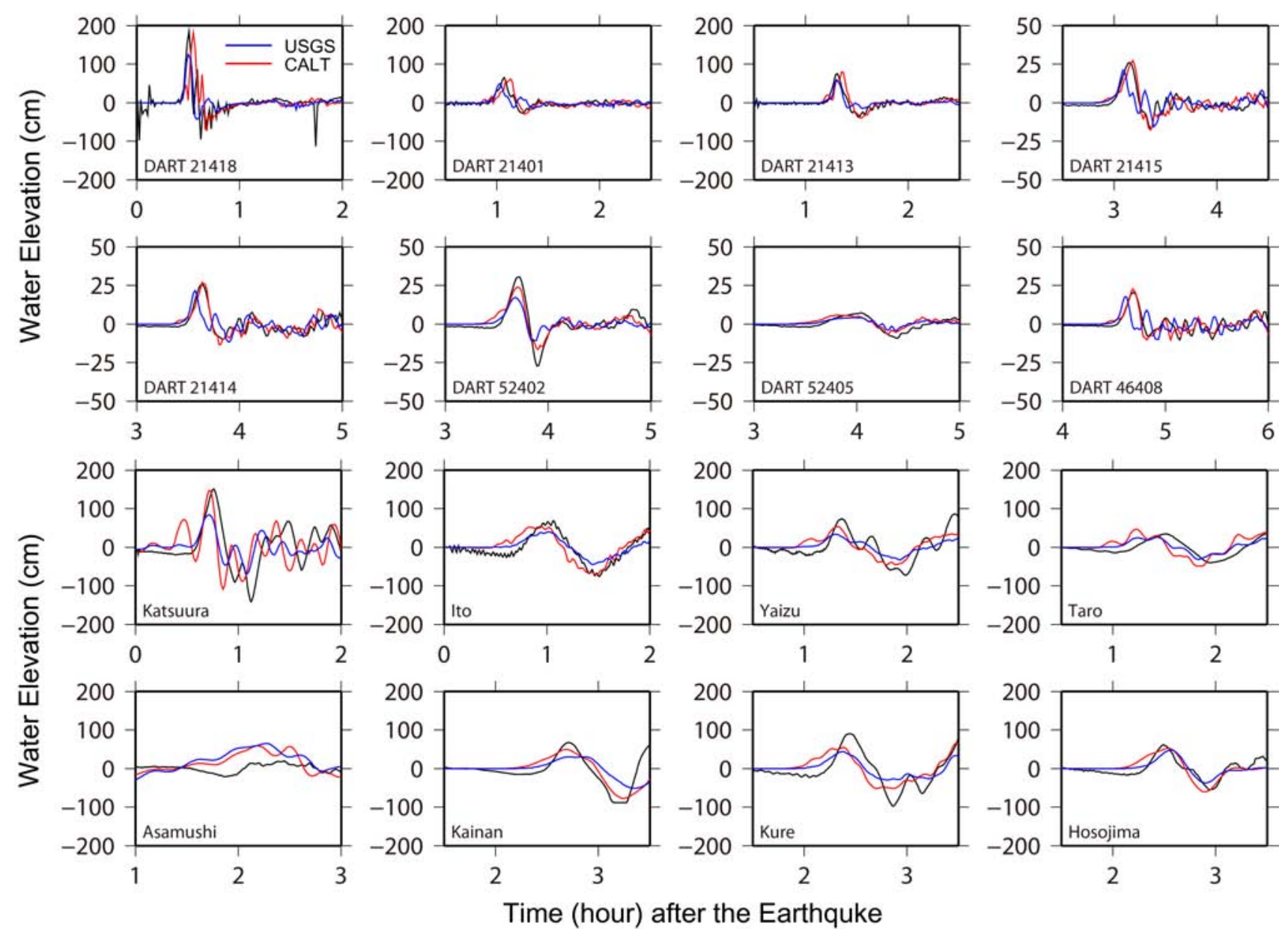

Time (hour) after the Earthquke

Fig. (4). Computed time series of water displacement from the eight DART buoys and eight tide gauge stations. The blue line indicates the simulation using the USGS fault model, and the red line indicates the simulation using the CALT fault model with the numerical method. The black line shows the filtered tsunami from the observed water displacement. The time axis starts at the time of the earthquake. 


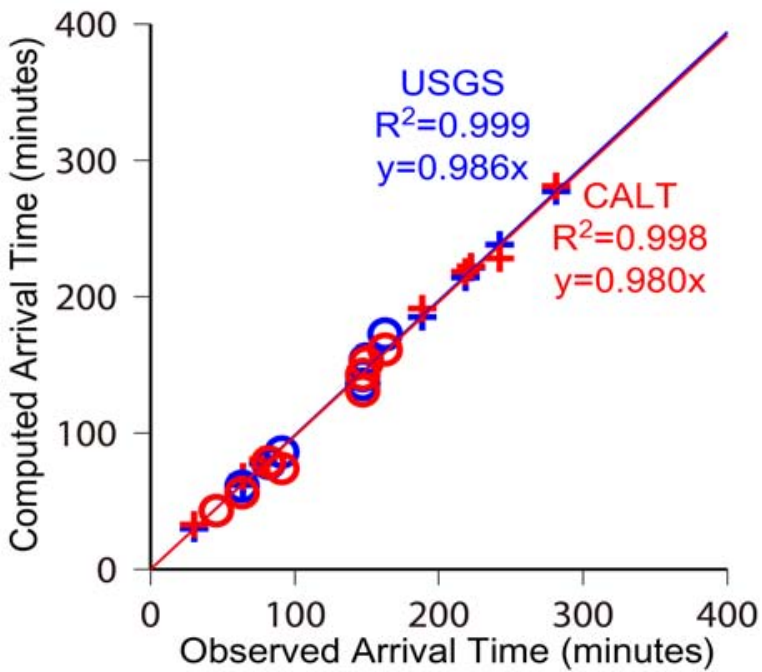

(a) Travel times of the first tsunami wave

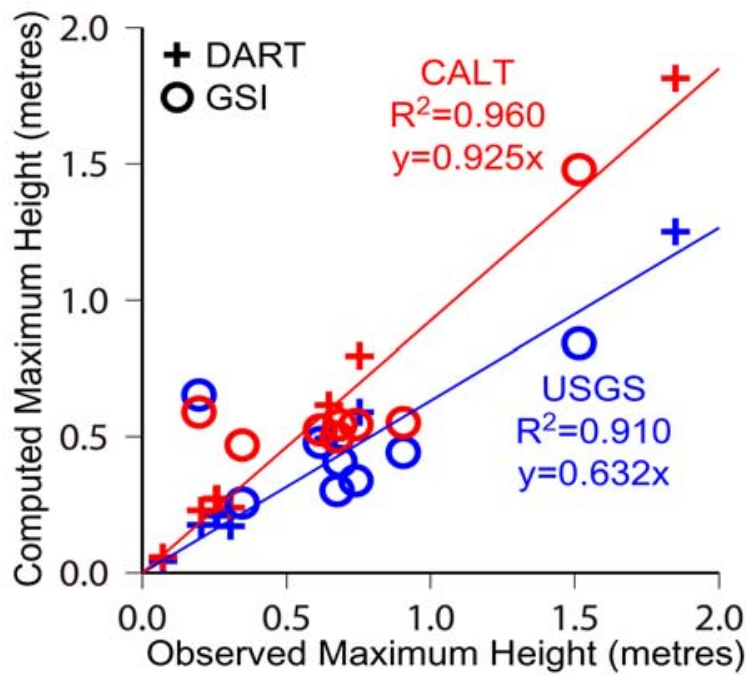

(b) First tsunami wave heights

Fig. (5). Comparison of (a) the observed and computed travel times of the first tsunami wave and (b) the first tsunami wave heightsfor Heya (USGS) and Simons' (CALT) fault models. The plus symbols indicate the DART buoys data, and the circle symbols indicate the tidal observation data (from Geospatial Information Authority of Japan).
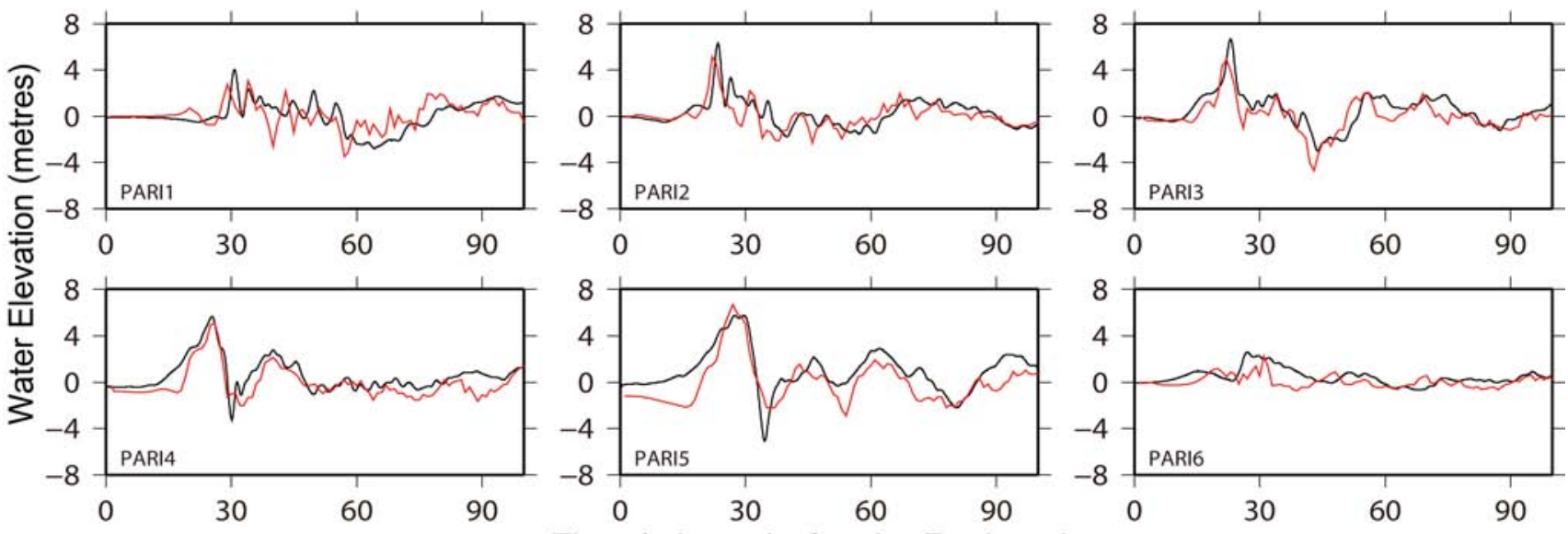

Time (minutes) after the Earthquake

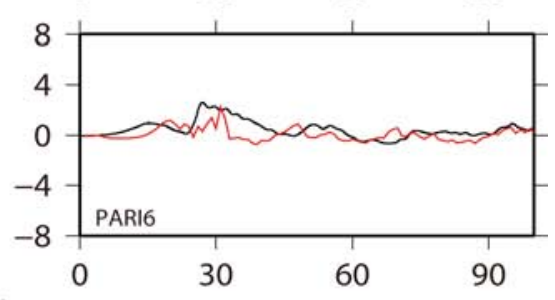

Fig. (6). Observed and computed time series of water displacement at the six GPS buoys that were placed by the Port and Airport Research Institute. The black line shows the filtered tsunami from the observed water displacement, and the red line indicates the simulation using the CALT model with the numerical method. The time axis starts at the time of the earthquake.

The comparison of the maximum tsunami wave height and arrival time of the peak wave shows good correlation in the GPS wave buoy. Fig. (7) shows the distribution of the computed wave heights along the Japanese coast in comparison with the distribution of the observed runup heights. The wave height along the coast was treated in the last sea grid point neighbouring the land grid point. This can have the difference with the exact wave height because the model grid has finite area. The total of 1415 observed runup heights within $1 \mathrm{~km}$ from the coastline to land from all surveyed data are plotted. For the comparison between the computed and observed heights the last sea grid points closed by the observed points are selected to the total of 744 points. The computed wave heights, on average, are smaller than the observed runup heights that are shown in Fig. (8); the ratio between the computed and observed values is 0.576 , and the coefficient correlation is $\mathbf{R}^{2} \sim 0.7$.
Numerical simulations of tsunami runup with high accuracy require high computer resources, and some runup corrections are used for prognostic purposes. For estimation of wave height in harbour the Green formula is used [19], meanwhile for runup heights on the coast analytical theory of long wave runup on a plane beach is applied [4]. Here we use last approach to estimate tsunami runup heights based on calculations with the Princeton Ocean Model. The time series that were computed by the numerical simulation of the water elevation on the last sea grid points are converted to the displacement of the water on the shore by the following formula:

$$
R(t)=\int_{0}^{t-T} \sqrt{(t-\tau)^{2}-T^{2}} \cdot \frac{d^{2} \eta(x=L, \tau)}{d \tau^{2}} d \tau
$$



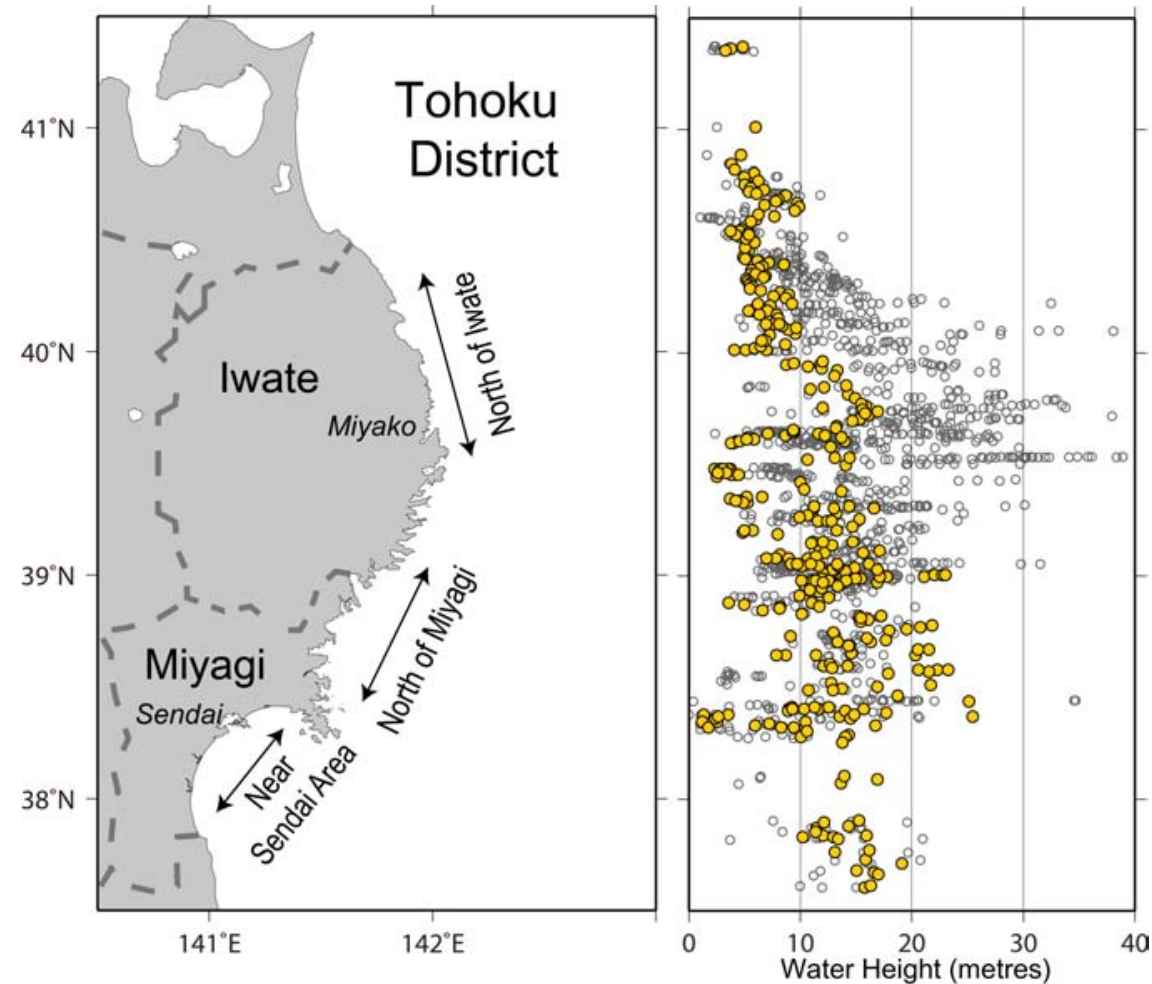

Fig. (7). Comparison of the observed runup heights and computed water heights in the Iwate and Miyagi areas. The black circles indicate the observed runup heights, and the yellow dots indicate the computed water heights.

where $R(t)$ is runup oscillations on the shore, $\eta(x, t)$ is water oscillations in the last sea points where the non-reflected boundary conditions are applied, $T$ is the travel time of the wave and $\mathrm{L}$ is the distance from this point to the shore. Here, $t=0$ corresponds to the wave that is approaching the last sea grid point. According to nonlinear theory, the extreme of $R(t)$ yields the maximal runup height of the tsunami wave. Details of the analytical solution are provided by [4].

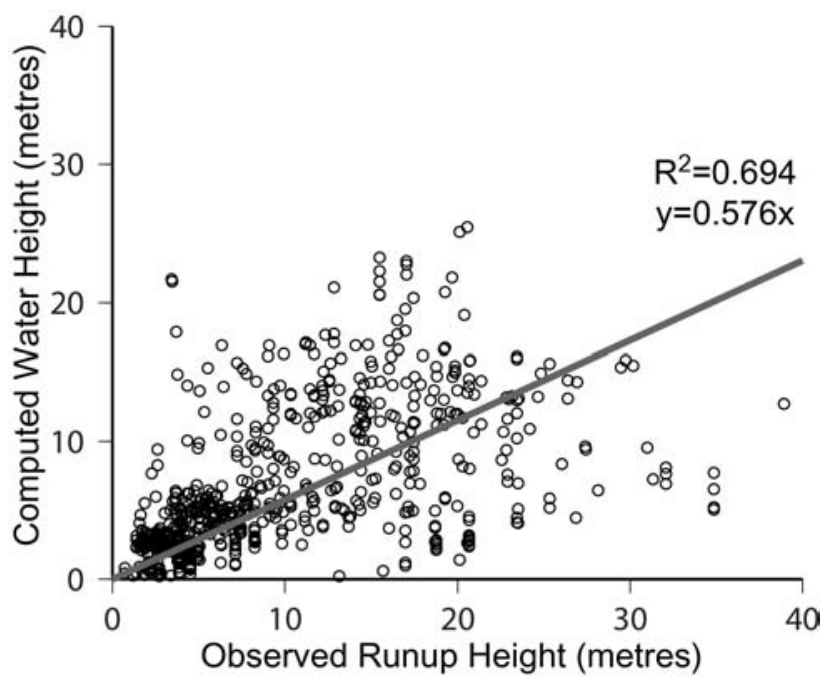

Fig. (8). Correlation between computed wave heights and observed runup heights.

Fig. (9) shows the distribution of the computed and observed runup heights along the Japanese coast. On average, the agreement between the computed and observed runup heights is slightly better than between the computed wave heights and observed runup heights. In particular, the proportionality coefficient between the computed and observed runup heights is 0.684 (Fig. 10). This result demonstrates the important role of the wave transformation and runup stage to explain the observed tsunami characteristics. For the Japanese coast, the amplification factor is nearly two (see Fig. 11).

Meanwhile, the computed runup heights deviate from the observed heights, and precise 2D computations of the runup stage are required to explain the observed data in each coastal location. Recently, such computations have been completed for the central Sanriku coast [20]. A good comparison is shown in Fig. (12). Our approach with the 1D computation is less accurate, but it can be completed in a short time with little computer processing power.

\section{IMPROVED ESTIMATIONS OF TSUNAMI RUNUP HEIGHTS}

As it was shown above, the use of the 1D analytical correction to the whole Japanese coast can not be done with high accuracy taking into account the complicated character of the coastal morphology. The second problem is that computer spatial step is larger then applied in the field survey measuring of tsunami heights. As a result, several different observed heights are compared with one computed height, see Fig. (9). Really, it is necessary to average observed data before comparison with computed results that requires hard work taking into account that number of measurements is more 5,000. After spatial averaging over 10 angle minute interval, the agreement between computations and observations is significantly better (Fig. 13). 

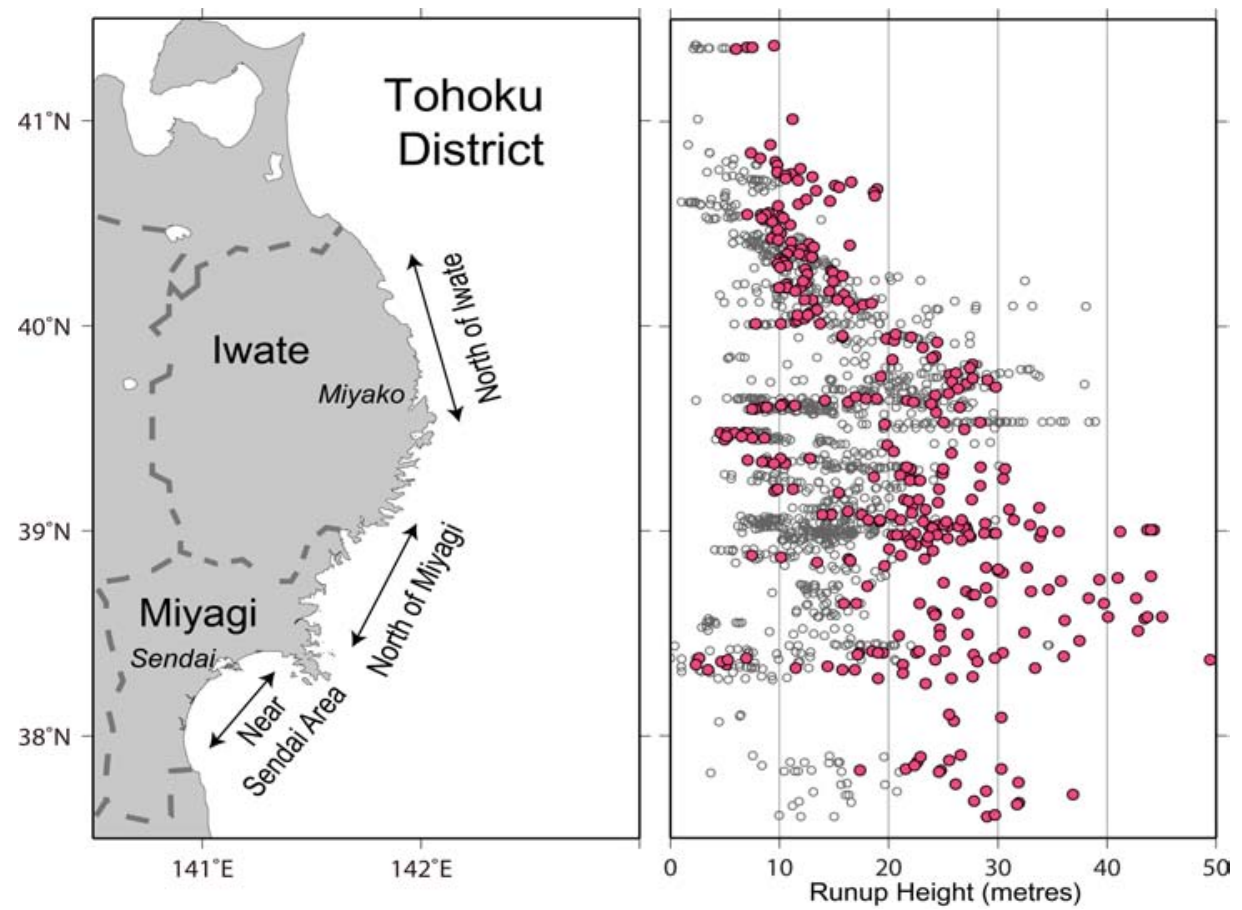

Fig. (9). Comparison between the observed and computed runup heights in the Iwate and Miyagi areas. The black circles indicate the observed runup heights, and the red dots indicate the computed runup heights.

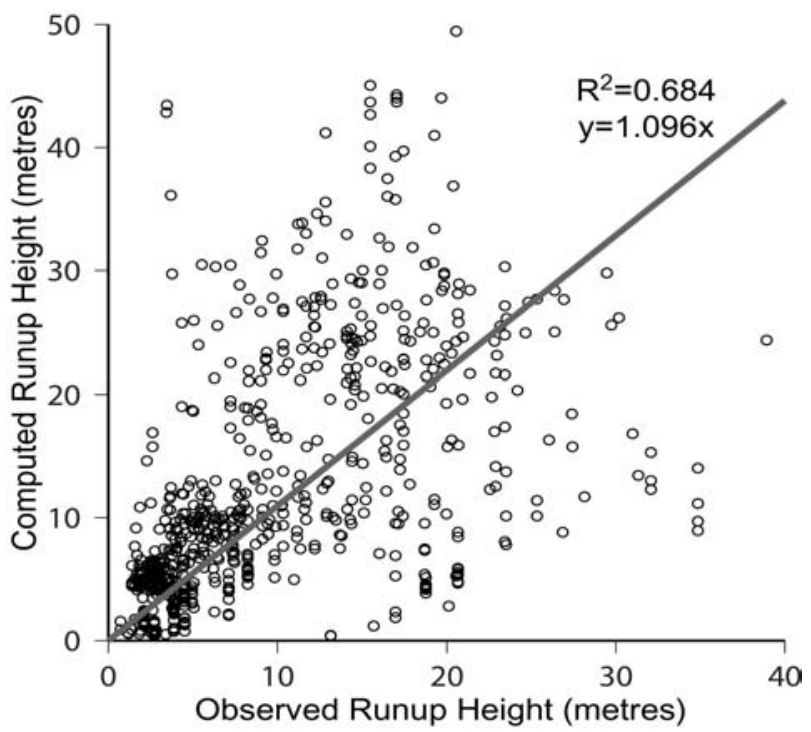

Fig. (10). Correlation between computed and observed runup heights.

Meanwhile some important conclusions can be done using the detail comparison between observed and computed runup heights with no averaging. Let us consider the coast of Japan to south from $37^{\circ} \mathrm{N}$ which was not analyzed early. The computed and observed runup heights are shown in Fig. (14) (last point in $300 \mathrm{~km}$ corresponds to $37^{\circ} \mathrm{N}$ and distance is accounted along the longitude). It is clearly seen that the comparison is quite good except 8 points. Taking into account that it is very small number of measured points, it can be concluded that comparison is well.

Such 8 points where the difference is very high should be specially analyzed. The bottom or land topography is very complicated in these points for use of 1D analytical theory. Let us delete such points from the list. The modified comparison is presented in Fig. (15). It looks significantly better, demonstrating a good applicability of the 1D theory for averaged estimates of tsunami runup heights. It is important to mention that the computed values of runup heights in general exceed observed values, in some points in 2-3 times. This disagreement is related with big dissipation of the tsunami wave energy on the coast pointed early for the 2004 tsunami in Banda Aceh [21, 22]. Analytical theory of long wave runup on a coast is developed for ideal fluid and could not describe wave friction.

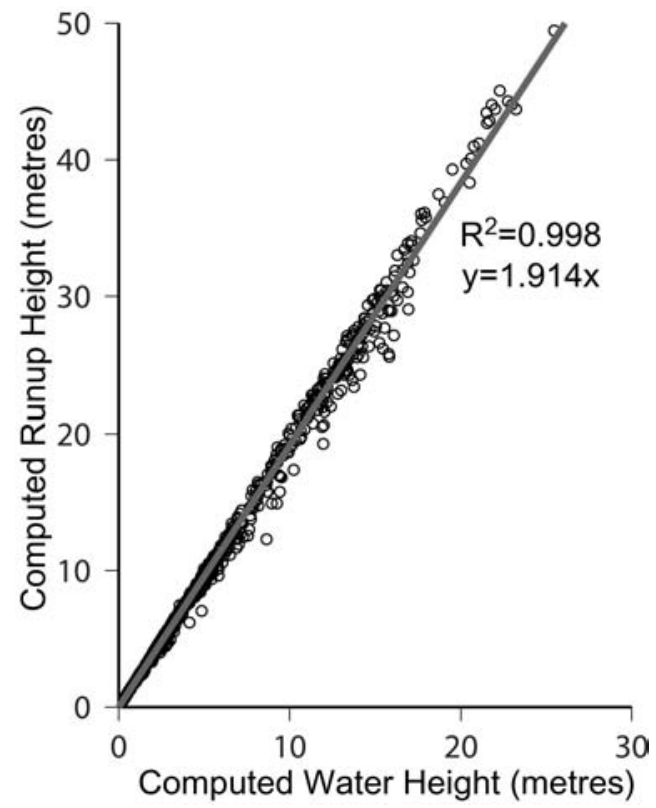

Fig. (11). Comparison of the computed water and runup heights. 


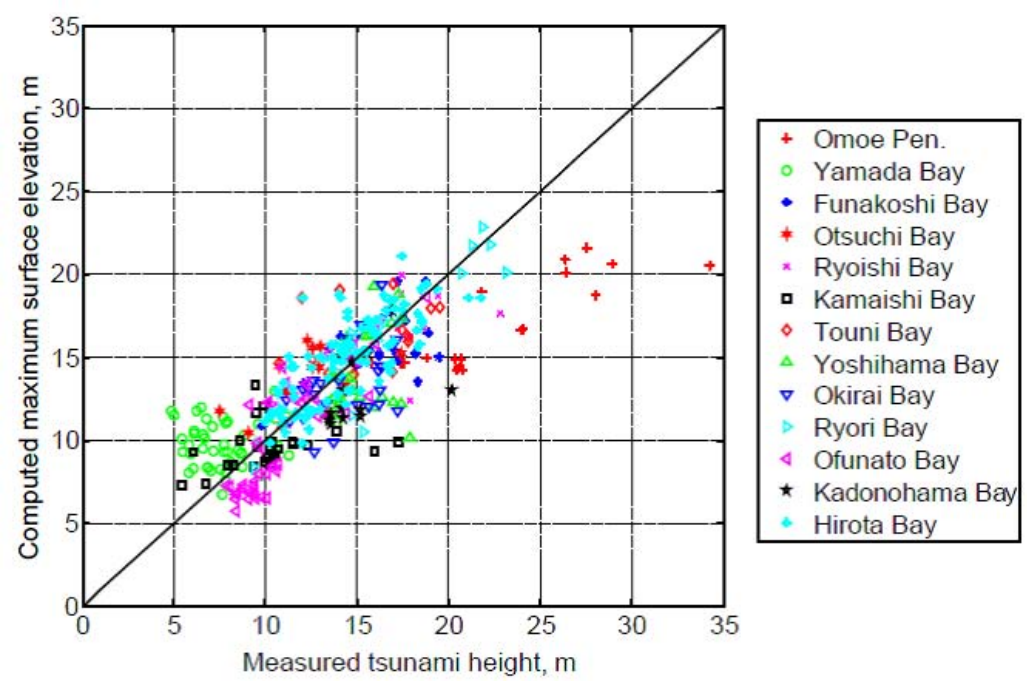

Fig. (12). Comparison of computed and observed runup heights that were obtained from precise numerical simulations (Shimozono et al., 2012).

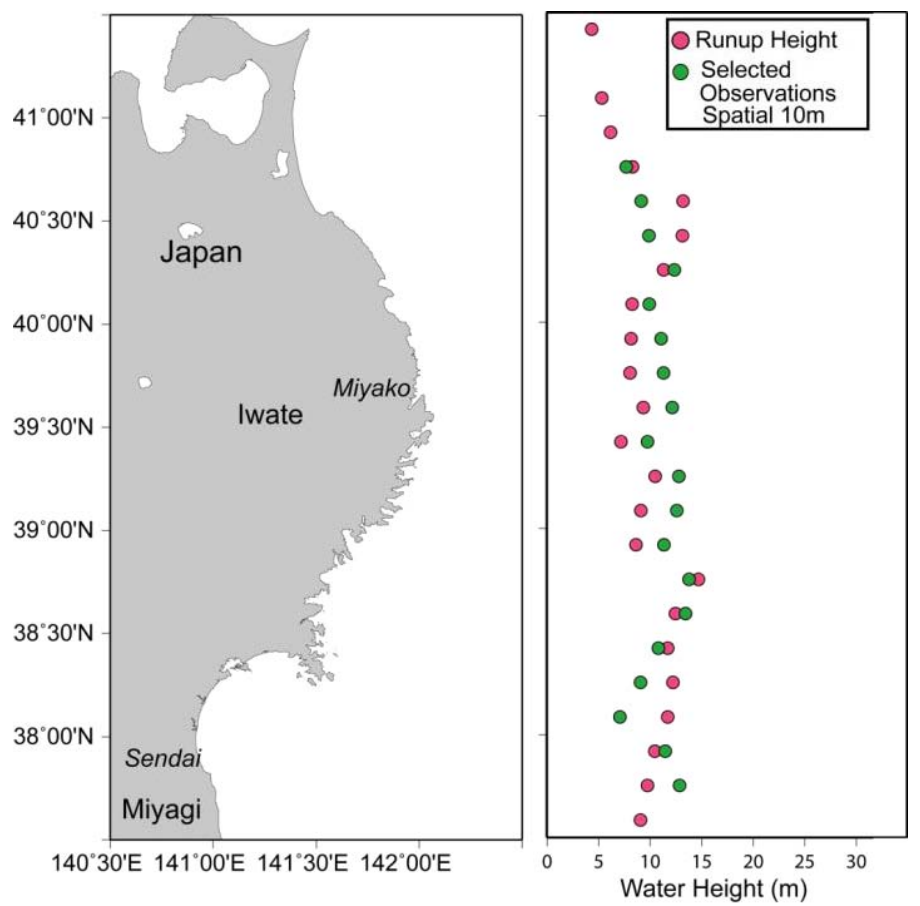

Fig. (13). Comparison of computed and observed runup heights after spatial averaging on 10 angle minutes.

\section{SUMMARY}

A numerical simulation of the 2011 Japanese tsunami is performed with Princeton Ocean Model. The finite fault model of the California Institute of Technology [10] is selected to estimate the tsunami wave characteristics. The tsunami data that were recorded by eight DART buoys and eight tidal gauges are good explained by the numerical results. The Princeton Ocean Model and the 1D analytical theory of long wave runup on a coast are applied to explain the tsunami runup heights on the Japanese coast. In general, the wave amplifies by a factor of two as it climbs the coast. The results of our numerical simulations of the 2011 Japanese tsunami confirm the applicability of the rapid method of estimating runup heights, which was suggested by [4] to describe roughly the observed averaging distribution of runup heights. Meanwhile, our analysis demonstrates that features of complicated bathymetry and land topography can play significant role in amplification of tsunami waves on the coast which are not described by the 1D analytical theory of long wave runup on a plane beach. Also effect of bottom friction is very important for catastrophic tsunami when wave flow penetrates inland on large distances, and this should be included in the theoretical model.

\section{CONFLICT OF INTEREST}

The authors confirm that this article content has no conflicts of interest.

\section{ACKNOWLEDGEMENTS}

The study was supported by a grant from KIOST for the project of the development of the marine environmental im- 


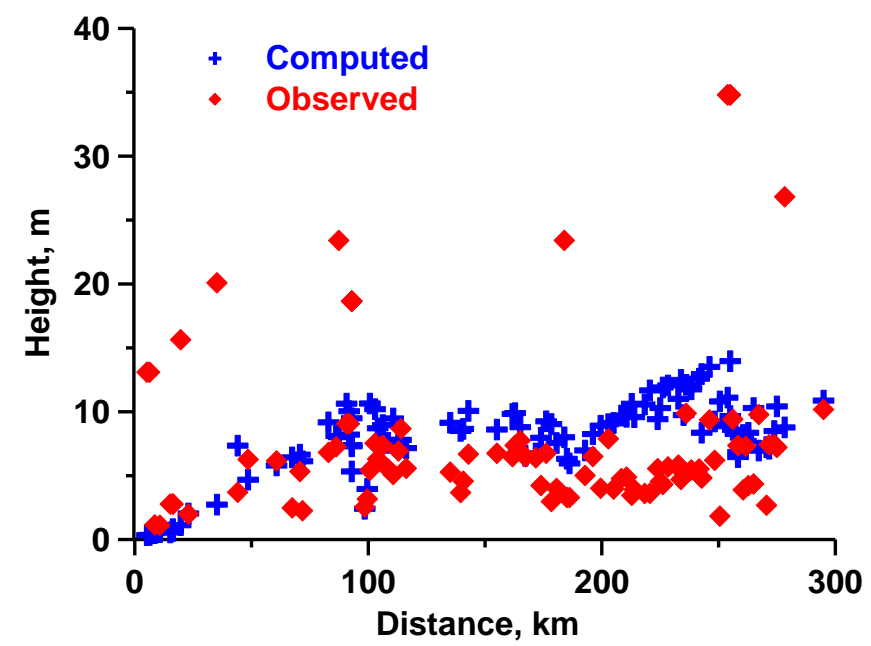

Fig. (14). Comparison of computed and observed runup heights for coastal area to south from $37 \mathrm{~N}$.
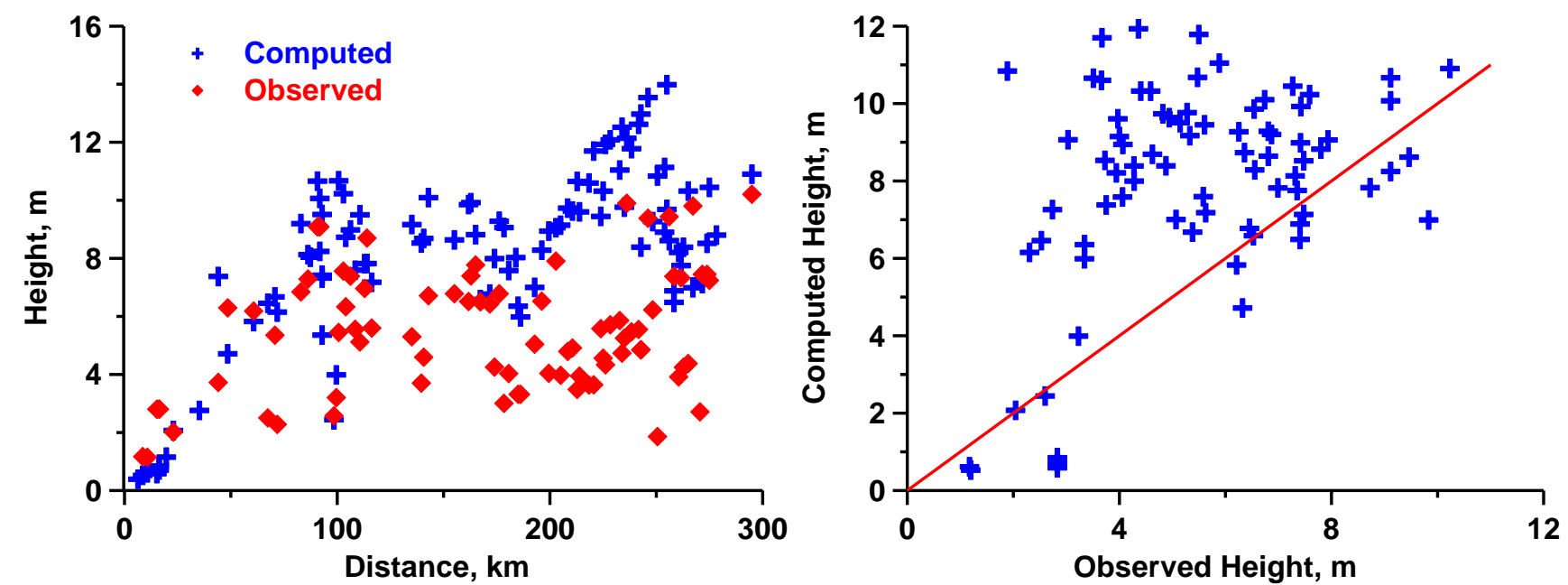

Fig. (15). The same as in Fig. 13 with eliminating of "big" points.

pact prediction system. Partially EP is supported by the Program "Scientific-Pedagogical Personnel of Innovative Russia for 2009-2013” and RFBR grant (11-05-00216).

\section{REFERENCES}

[1] Tsuji Y, Satake K, Ishibe T, et al. Field surveys of tsunami heights from the 2011 off the Pacific Coast of Tohoku, Japan Earthquake. Bull Earthq Res Inst Univ Tokyo 2011; 86: 29-279.

[2] Mori N, Takahashi T, The 2011 Tohoku Earthquake Tsunami Joint Survey Group. Nationalwide post event survey and analysis of the 2011 Tohoku Earthquake Tsunami. Coast Eng J 2012; 54: 1250001.

[3] Hokkaido Tsunami Survey Group. Tsunami devastates Japanese coastal Regions. EOS Trans AGU 1993; 74: 417-432.

[4] Choi BH, Kaistrenko V, Kim KO, Min BI, Pelinovsky E. Rapid forecasting of tsunami runup heights from 2-D numerical simulations. Nat Hazards Earth Syst Sci 2011; 11: 707-714.

[5] Min BI, Choi BH, Kim KO, Kaistrenko VM, Pelinovsky EN. Hindcast simulation of 2011 Great East Japan Earthquake Tsunami. Asian and Pacific Coasts 2011; 99-106. doi:10.1142/9789814366489_0011.

[6] Blumberg AF, Mellor GL. A description of three-dimensional coastal ocean circulation model. Three dimensional coastal models, Norman S. Heaps, ed., American Geophysical Union, Washington, D.C. $1987 ; 1-16$.

[7] Oey L. A wetting and drying scheme for POM. Ocean Modelling 2005; 9: 133-150.
[8] Mellor GL, Yamada T. Development of a turbulence closure model for geophysical fluid problems. Rev Geophys Space Phys 1982; 20 (4): 851-75.

[9] Heyes G. Finite Fault Model, Updated Result of the Mar 11, 2011 Mw 9.0 Earthquake Offshore Honshu, Japan; 2011. Available from: http://earthquake.usgs.gov/earthquakes/eqinthenews/2011/usc0001xgp/finite_fault.php

[10] Simons M, Minson SE, Sladen A, et al. The 2011 Magnitude 9.0 Tohoku-Oki Earthquake: Mosaicking the Megathrust from Seconds to Centuries. Science 2011; 332 (6036), 1421-5.

[11] Okada Y. Surface deformation due to shear and tensile faults in a half-space. Bull Seismol Soc Am 1985; 75: 1135-54.

[12] Japan (East Coast of Honshu) Tsunami, March 11, 2011. NOAA/PMEL/Center for Tsunami Research. Available from: http://nctr. pmel.noaa.gov/honshu20110311/

[13] Butterworth S. On the theory of filter amplifiers. Experimental Wireless \& the Wireless Engineer 1930; 7: 536-41.

[14] Maeda T, Furunura T, Sakai S, Shinohara M. Significant tsunami observed at ocean-bottom pressure gauges during the 2011 off the Pacific coast of Tohoku Earthquake. Earth Planets Spaces 2011; 63: 803-8.

[15] Nosov MA, Kolesov SV, Levin BW. Contribution of horizontal deformation of the sea floor into tsunami generation near the Coast of Japan on March 11, 2011. Doklady Earth Sciences 2011; 441: $1537-42$.

[16] The 2011 Tohoku Earthquake Tsunami Joint Survey Group. Nationwide field survey of the 2011 Off the Pacific Coast of Tohoku Earthquake Tsunami. J Japan Society of Civil Engineers, Series B 2011; 67: 63-6. 
[17] National Geophysical Data Center / World Data Center (NGDC/ WDC) Global Historical Tsunami Database homepage on the Internet. Available from: http://www.ngdc.noaa.gov/hazard/tsu_ db.shtml

[18] IOC/UNESCO. Casualties for the Earthquake and Tsunami of March 11, 2011. IOC/UNESCO Bulletins 2011. Available from: http://www.ngdc.noaa.gov/hazard/tsunami/pdf/

[19] Reymond D, Okal EA, Hebert H, Bourdet M. Rapid forecast of tsunami wave heights from a database of pre-computed simulations, and application during the 2011 Tohoku tsunami in French Polynesia. Geophysical Research Letters 2012; 39: L11603. doi: 10.1029/2012/GL051640.
[20] Shimozoni T, Sato S, Okayasu A, et al. Propagation and inundation characteristics of the 2011 Tohoku tsunami on the central Sanriku coast. Coast Eng J 2012; 54: 125004.

[21] Lavigne F, Paris R, Grancher D, et al. Reconstruction of tsunami inland propagation on December 26, 2004 in Banda Aceh, Indonesia, through field investigations. Pure and Applied Geophysics 2009; 166: 259-81.

[22] Paris R, Wassmer P, Sartohadi J, et al. Tsunamis as geomorphic crises: lessons from the December 26, 2004 tsunami in Lhok Nga, West Banda Aceh (Sumatra, Indonesia). Geomorphol 2009; 104: 59-72.

(C) Choi et al.; Licensee Bentham Open.

This is an open access article licensed under the terms of the Creative Commons Attribution Non-Commercial License (http://creativecommons.org/licenses/by-nc/3.0/) which permits unrestricted, non-commercial use, distribution and reproduction in any medium, provided the work is properly cited 